\title{
Social Workers' Role in the Disproportionality of African American Students in Special Education
}

\author{
Kristen Faye Bean
}

\begin{abstract}
There is an overrepresentation of African American students in special education. Research on this phenomenon has primarily focused on educators within schools. School social workers are in unique positions to impact the disproportionality. Patricia Collins' Domains-of-Power Framework is used to demonstrate how school social workers can practice transformational resistance to eliminate the overrepresentation of African American students in special education. School social workers should: 1) attend IEP meetings and conduct home visits and biopsychosocial evaluations with students who are being assessed for special education services, 2) offer to evaluate and conduct home visits with students whom teachers deem to be "at-risk" to prevent inappropriate assessments for special education, 3) create a school culture of acceptance of difference, and 4) ask themselves how they individually foster racial domination or emancipation in their daily actions.
\end{abstract}

Keywords: Disproportionality, special education, Domains-of-Power Framework, Individuals with Disabilities Education Act, African American students

There is an overrepresentation of African American students in special education classrooms (Artiles, Kozleski, Trent, Osher, \& Ortiz, 2010; Blanchett, 2006; Harry \& Anderson, 1994; Mills, 2003; Skiba, Poloni-Staudinger, Gallini, Simmons, \& FegginsAzziz, 2006; Skiba et al., 2008). African American students have been historically disadvantaged in public education and have suffered poorer outcomes in rates of school retention, employment, and poverty status than other people (Chemerinksy, 2002; U.S. Census Bureau, 2010). Although special education is designed to provide personalized support for students with disabilities, inclusion of students with disabilities in regular education settings is preferred. The preference for inclusion is due to research that demonstrates detrimental effects for students who are separated from regular education and their typical peers (Brown, Higgins, Pierce, Hong, \& Thomas, 2003; Freeman \& Alkin, 2000; Hanushek, Kain, \& Rivkin, 2002; Harry \& Anderson, 1994). For over two decades, previous research on the disproportionality of African American students in special education has primarily focused on teachers and schools as the target of intervention to decrease the disproportionality (Artiles et al., 2010). A new technique to impact disproportionality is necessary. School social workers need to take advantage of their unique role in students' lives that empowers them to impact the disproportionality. Patricia Collins’ Domains-of-Power Framework will be used to demonstrate how school social workers can practice transformational resistance to eliminate the overrepresentation of African American students in special education.

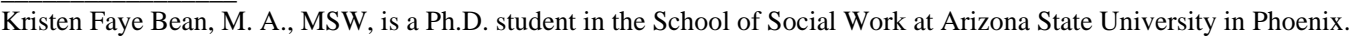




\section{BACKGROUND OF THE DISPROPORTIONALITY OF AFRICAN AMERICAN STUDENTS IN SPECIAL EDUCATION}

African American students are overrepresented in special education classrooms (Artiles et al., 2010; Skiba et al., 2006). While African American students represent only $17 \%$ of school-age children, they represent one-third of students identified as experiencing mental retardation (Skiba et al., 2008). The identification of a disability alone does not cause students to be placed in special education classrooms. The decision to place a student in a regular education, special education, or part-time resource classroom depends on the opinion of students, teachers, school principals, and students' families. African American students in Indiana who experienced an emotional disturbance, mild mental retardation, moderate mental retardation, learning, speech, or language disability were more likely to be placed in a restrictive setting, such as a special education classroom, than other students with similar disabilities (Skiba et al., 2008).

While statistics about the disproportionality exist, debates occur on whether or not disproportionality is a problem. Scholars who argue that disproportionality is a problem report the negative impact of inappropriately placing African American students in special education. For example, a study of 222 students in special education found that they were more likely than students in regular education to experience alienation in school, felt like their education would not contribute to their future and that breaking rules in school was fine (Brown et al., 2003). Another study showed that students in general education performed better on measures of academic achievement and social competence than students in restrictive classrooms (Freeman \& Alkin, 2000). Longitudinal data shows that students with disabilities in special education are not improving their outcomes at the same rate as their peers in regular education (Artiles et. al., 2010). Those who posit that disproportionality is not a problem argue that special education is a safety net for students who are falling behind in regular education classes. For example, Freeman and Alkin (2000) found that children with mental retardation in general education did not attain social acceptance ratings as high as their typically developing peers. The Individuals with Disabilities Education Improvement Act (IDEA, 2004) mandated that special education classrooms have low teacher-student ratios, individualized education, and high expenditures per pupil, which are desirable characteristics.

\section{HISTORICAL DISADVANTAGE OF AFRICAN AMERICAN STUDENTS IN PUBLIC EDUCATION}

While examining the exclusion of African American students in education, it is important to reflect on their history of segregation in public education. African American

students in public education were legally segregated into different schools than white students prior to 1954, when the Brown v. Board of Education declared that it was unconstitutional for state laws to establish separate public schools for white and black students (Chemerinsky, 2002). A decade later, Title IV of the Civil Rights Act tied federal funds to the elimination of segregation. It mandated that students should be assigned to public schools regardless of race, color, religion, or national origin 
(Chemerinksy, 2002). The integration of white and black students in the south rose to $32 \%$ in 1968 and to 91\% by 1973 (Chemerinsky, 2002). Although the trend of desegregation showed potential, scholars have documented a resegregation that has occurred in public schools since the 1970s due to white flight to suburbs, disparities in school funding, and recent Supreme Court decisions (Chemerinksy, 2002). Historical disadvantage has impacted African Americans; they lag behind in rates of school retention, employment, and poverty (U.S. Census Bureau, 2010). The overrepresentation of African American students in special education may represent another form of segregation that has detrimental effects on student outcomes.

\section{RESEARCH FOCUSED ON TEACHERS AND SCHOOLS}

The majority of research on the overrepresentation of African American students in special education has focused on teachers and schools. The process of identifying a child with a disability and the decision of classroom placement occur primarily within the school environment. The identification of a disability is first initiated by a teacher. The teacher makes a referral to a school psychologist to assess the child (Harry \& Anderson, 1994; Skiba et al., 2008). Ideally, the school psychologist objectively administers valid and reliable intelligence tests. If the tests determine that the student has a disability diagnosis, an Individualized Education Plan (IEP) meeting is scheduled with a special education teacher, regular education teacher, local educational agency representative, campus administrator, the student with a disability if he or she is at least 14 years old, and other people who are familiar with the student (Individuals with Disabilities Education Improvement Act, 2004). The IEP meeting is held to discuss the student's disability status and classroom placement. The IEP team decides if the student should be placed in a regular education classroom, special education classroom, and/or receives resource hours. Classroom placement and hours are negotiated during the meeting (Individuals with Disabilities Education Improvement Act, 2004). Because of the teacher's knowledge about the student's progress in his or her classroom, the teacher's opinion is given much weight during the negotiation of the student's classroom placement (Harry \& Anderson, 1994).

\section{SCHOOL SOCIAL WORKERS' ROLE IN THE DISPROPORTIONALITY}

Most research has focused on how teachers can impact the disproportionality of African American students in special education, yet school social workers are not constrained within schools and are uniquely situated to understand students' environmental factors that impact their development and use the students' environment as a resource. Teachers and school administrators are primarily limited to supporting students within schools, which can lessen their access to and understanding of students' families and communities. Social workers' roles and responsibilities, ethical responsibility for social justice, and participation in child study teams enable them to make a difference in the disproportionality. Literature that has discussed social work and disproportionality presents structural, disciplinary, cultural, and interpersonal methods in which social workers can decrease the overrepresentation of African American students in special education. 
The roles and responsibilities of school social workers span from micro interventions, such as direct prevention and intervention activities with students, to macro interventions, such as creating positive school climates. A study of 606 school social workers found that most reported the use of three-tiered interventions with students, including primary, secondary and tertiary interventions. Primary interventions included prevention efforts, such as coordinating services for students in the community. Secondary interventions were described as early identification of nonacademic barriers and targeted interventions to address the barriers. Tertiary interventions include direct counseling and mental health support after a student has an identified need (Bronstein, Ball, Mellin, Wade-Mdivanian, \& Anderson-Butcher, 2011). Based on their training, social workers should view students in their social environment, including school climate. School social workers have the responsibility to use their knowledge of multi-systemic and ecological perspectives to create positive school climates, resulting in caring and responsive schools (Hopson \& Lawson, 2011). Although social workers are trained in ecological and systemic influences on development, a majority of school social workers have focused on the child or micro level and report little communication with teachers (Kelly, Frey, \& AndersonButcher, 2010).

In addition to social workers' education in the ecological perspective, social workers have an ethical responsibility for social justice. One of the ethical principles determined by the National Association of Social Workers' (NASW) Code of Ethics (National Association of Social Workers, approved 1996, revised 1999) is that social workers challenge social injustice. The NASW Code of Ethics reports, "Social workers strive to ensure access to needed information, services, and resources; equality of opportunity; and meaningful participation in decision making for all people" (National Association of Social Workers, approved 1996, revised 1999). This section of the Code of Ethics illustrates the professional responsibility that social workers have to practice transformational resistance to the disproportionality of African American students in special education. Transformational resistance includes a critique of oppression and a desire for social justice (Solorzano \& Bernal, 2001). Social workers must be aware of the oppression of African American students in special education and critique the oppressive conditions and structures that dominate African American students.

The few articles that have been published about social work's role in the disproportionality of African American students in special education have researched and discussed structural, disciplinary, cultural, and interpersonal means in which social workers can decrease the disproportionality. For example, social workers have a potentially strong voice in deciding the diagnosis and placement of students in special education due to their role in child study teams, yet structural issues limit their participation. The child study teams determine if a student is eligible and needs special education services (Individuals with Disabilities Education Improvement Act, 2004). School social workers are assigned to complete a social and developmental study to ensure that specific diagnostic criteria have been met (Ebersole \& Kapp, 2007). The social and developmental study of students includes a home visit to gain an understanding of the child's context and environment. Although it is not mandatory, school social workers may be invited to attend an IEP meeting, where the child's 
diagnosis is reviewed and classroom placement is determined. Social workers may be the only member of the team to have visited the student's home environment, met extended family members, and have knowledge of community resources that can support the student. Social workers can express their understanding of the student's home environment, which could reveal how the environment impacts the student's developmental and educational progress. This unique knowledge has the potential to decrease the overrepresentation of African American students in special education. As Joseph, Slovack, and Broussard (2010) reported in their conceptual article on social work's privilege and duty to confront the segregation of students by curriculum: "If not us, then who?” (p. 17). For example, if a student's parents are going through a divorce, the student may exhibit externalizing behaviors and be easily distracted. Even though the student may appear to have a learning disability, the social worker's knowledge of struggles in the student's home might determine that the student needs therapeutic support, rather than special education services.

Although social workers have the potential to make a difference in disproportionality by conducting social and developmental studies for child study teams, research has shown that child study teams do not always follow strict criteria and social workers are not mandated members on IEP teams. Ebersole \& Kapp (2007) conducted an analysis of all students identified as mentally retarded in a large Midwestern city during May 2005 to assess if the child study teams adhered to district policy in certification of students served under the category of mental retardation. The guidelines to determine a student as mentally retarded included: 1) reported IQ of less than 70 and 2) at least two scores less than 70 on each of the Vineland Adaptive Behavior Scale (VABS) domains: communication, daily living skills, socialization, and motor skills, or 3) one set of the domain scores and/or the composite score on the VABS and an academic achievement score less than 70 . The study found a significant difference between the rates of placement as mentally retarded using precise criteria between African American (24.1\%) and White (52.3\%) students (Ebersole \& Kapp, 2007). In addition, they also found that only $16 \%$ of the child study teams that did not adhere to district policy received an evaluation of the certification from a supervisor. Ebersole \& Kapp (2007) suggested that strict adherence standards must be followed in all child study teams.

The disciplinary and cultural aspects of social workers' role were discussed concurrently by scholars. Mills (2003) expressed that culture impacts the disciplinary aspect of social work services. Mills (2003) explained that social workers can help to "rule out" the impact of culture and other aspects of a student's social environment as explanations for a student's inability to be successful in a general education classroom. For example, a student's cultural norms may differ from a teacher's cultural norms, which could negatively result in the teacher's disciplinary action of the student. Social workers can help to "rule out" this cultural impact by learning about the student's culture and communicating with the teacher about cultural differences. Before students are identified as falling behind in the general education classroom, social workers should engage in preventative practices by responding to students' behaviors (Mills, 2003).

The interpersonal ways in which social workers can decrease the overrepresentation of African American students in special education is to recognize our own racial bias and 
discriminatory acts. Discussions of racism are ubiquitous in the literature about social work and disproportionality in special education. As Joseph, Slovak, and Broussard (2010) explain, “'race’ and 'ability’ have a powerful hold over some in society” (p. 9). This includes social workers. In order for social workers to advocate for structural change and play a larger role in decreasing the disproportionality, they must be able to recognize their own racial bias and discriminatory acts, no matter how subtle the biases or acts may be.

\section{DOMAINS-OF-POWER FRAMEWORK}

Patricia Collins created the Domains-of-Power Framework in response to other theories that dichotomized racial inequality as caused by either institutional or personal factors. Collins' framework posits that racial inequality is caused by both institutional and personal factors. Domains-of-Power Framework posits that racism is a system of power with four domains: structural, disciplinary, cultural, and interpersonal (Collins, 2009). According to the Framework, to impact the disproportionality of African American students in special education, the power within and across all four domains must be addressed.

The structural domain of power demonstrates how racial practices are organized by social institutions. Collins (2009) explains that "this is the structure of how racism as a system of power is set up, and how it is organized without anybody doing anything. This is the structure into which we are all born and we will leave behind when we die” (p. 53). The public school system is a structural domain of power that can manifest racist practices. One example of how the public school system manifests racial inequality is funding. School funding provided by property taxes is a structure that is set up in a way that impacts racial inequality. A school receives funding by taxes of property surrounding the school. Schools in lower socioeconomic neighborhoods receive less funding than schools in higher socioeconomic neighborhoods due to the lower property taxes in the area surrounding the schools. Minority students are more likely than white students to live in lower socioeconomic neighborhoods (Ladson-Billings, 2009).

The disciplinary domain of power includes rules and regulations organized by bureaucracies, but relies on people to practice surveillance of the system. To examine this domain of power, Collins (2009) suggests that we might ask the question, "How do implementation strategies reflect the racial and class composition of the classroom?” (p. 55). For example, assessments for special education are initiated by teachers, who are required by law to request evaluations of students who are unable to successfully accomplish school work at similar levels to their peers due to learning, emotional, or behavioral disabilities (Individuals with Disabilities Education Improvement Act, 2004). This policy may cause teachers to request evaluations for students even if they demonstrate a minor delay of understanding class material or present behavioral issues that distract from their learning in class. Parent participation is necessary during evaluations for special education services. Student classroom placement is determined during IEP meetings. As Blanchett (2006) explains, "Educators tend to see Whiteness as the norm and consequently the academic skills, behavior, and social skills of African American and other students of color are constantly compared with those of their White 
peers” (p. 27). This can be intimidating and may impact the willingness of minority students' parents to advocate for their child's classroom placement during IEP meetings (Blanchett, 2006). The disciplinary domain of power implies the need for an assessment of how the implementation strategies for special education placement might be impacting the disproportionality.

The cultural domain of power explores how people's ideas justify racial inequalities. Collins (2009) argues that popular media contain strong representations of the cultural domain of power. Racial stereotypes are represented in songs and music videos. The majority of media represent young women of color as "hos" and young men of color as "pimps" (Collins, 2009). Because adolescent students spend much of their time listening to music and watching television, they are highly influenced by the stereotypes of young men and women of color represented in the media. If minority students believe in the stereotypes, they may be less likely to try to succeed in school. Professionals within schools are also influenced by stereotypes of minority students portrayed in the media. The stereotypes may make people believe that the overrepresentation of minority students in special education is justified.

The interpersonal domain of power is where experiences shape race relations among one-on-one encounters between individuals in everyday life. People are given the opportunity to accept or resist racial inequality in their interactions with others (Collins, 2009). Regular education classes are more likely to be taught by female educators who may produce the norm of whiteness (Blanchett, 2006). This could have a negative impact on the understanding of the content taught among minority students and boys in the classroom. Female norms, such as being clean and quiet, may impact the behavioral success of boys, who are more likely to be rambunctious and louder than their female peers. White female teachers may be more likely to request a minority, male student to receive disciplinary actions and be assessed for disabilities than other teachers (Harry \& Anderson, 1994).

\section{CONCEPTUAL ASSUMPTIONS}

The Domains-of-Power Framework provides spheres in which social workers can practice transformational resistance of the overrepresentation of African American students in special education. In order for social workers to be able to resist the disproportionality they must be knowledgeable of diversity and disability issues, believe in an ethical responsibility to advocate for social justice, and have a role in the diagnosis and placement of students in special education. Drawing on social work education and ethics and educational policy, I make three assumptions:

\section{Assumption no. 1}

Social work education provides social workers with education on diversity and disability content. As prescribed in the Council on Social Work Education (CSWE) Educational Policy Accreditation Standards (EPAS) social workers should learn how to engage in diversity and difference in practice. Dimensions of diversity taught in social work education should include the intersectionality of age, class, color, culture, disability, 
ethnicity, gender, gender identity, immigration status, political ideology, race, religion, sex, and sexual orientation (Council on Social Work Education, 2008). It is assumed that social work students receive an education on diversity issues, such as culture, disability, ethnicity, and race, and continue to remember their education as they practice social work.

\section{Assumption no. 2}

Social workers are knowledgeable of and believe in the NASW Code of Ethics. The CSWE EPAS also requires that social work education include engagement in ethical decision-making using the NASW Code of Ethics (Council on Social Work Education, 2008). The NASW Code of Ethics states that social workers have an ethical responsibility to advocate for social justice (National Association of Social Workers, approved 1996, revised 1999). It is an assumption that all schools of social work teach courses using the NASW Code of Ethics and social workers believe in and plan to follow the NASW Code of Ethics.

\section{Assumption no. 3}

Social workers are members of the child study teams as prescribed in the IDEA. As demonstrated by Ebersole and Kapp (2007), child study teams have not always followed strict criteria established in the IDEA; therefore, it is an assumption that social workers are members of each child study team and conduct a social and developmental study for children.

\section{DOMAINS-OF-POWER FRAMEWORK AND THE FUTURE ROLE OF SOCIAL WORKERS}

School social workers can bring about transformational resistance and eliminate overrepresentation of African American students in special education by creating change within and across the structural, disciplinary, cultural, and interpersonal power domains.

\section{Structural}

The process of determining that a student has a disability is a structure that has manifested racial inequalities. Although social workers have been on child study teams, they have not been mandated members of IEP teams. The child study team decides whether or not a student fits the criteria for a disability diagnosis. The IEP team decides the student's classroom placement. The IDEA should mandate that school social workers are included in IEP team meetings. Social workers' unique position, which enables them to visit the student's home and community, is valuable in both child study and IEP team meetings.

Ensuring that school social workers are on the IEP teams is just the first step to change the structure of determining a disability diagnosis and classroom placement. School social workers must be required to conduct home visits and biopsychosocial evaluations prior to child study team meetings. During a biopsychosocial evaluation, social workers assess a person's biological, psychological, and social condition. This 
would allow the social workers to learn about the student's home life, culture, and developmental achievement and provide the IEP team with more knowledge about how the student's family and environment may impact his or her development.

\section{Disciplinary}

School social workers should engage in preventative practices with students, teachers, and administrators in schools. As Mills (2003) suggests, the impact of culture and other aspects of a student's environment need to be "ruled out" before determining that a student has a disability. Not only do social workers need to rule out environmental impacts on students' academic achievement and provide preventative services, they need to assess the appropriateness of the disciplinary actions of teachers and administrators for students who are labeled as "at-risk". Minority students are often labeled as "at-risk", which causes educators to participate in disciplinary practices with minority students more often than with White students (O’Connor, Hill, \& Robinson, 2009). The "at-risk" label can have detrimental effects on African American students. If educators believe all African American students are "at-risk" academically, any slight reason African American students demonstrate that they may need special education services could cause an educator to refer students to receive assessments. Social workers can request that teachers refer students to the school social worker if the teacher perceives the student is struggling academically. Collaborating with teachers may be new to school social workers, since a majority of them reported that they had little communication with teachers (Kelly, Frey, \& Anderson-Butcher, 2010). Social workers can prevent inappropriate referrals to special education services by conducting home visits with students who are labeled "at-risk" to determine if student needs are not academically based. If the student's needs are due to non-academic reasons, such as socioeconomic, social workers may be able to provide resources to resolve the issue.

\section{Cultural}

School social workers can impact the cultural domain of power by becoming knowledgeable about culture and creating a culture of acceptance of difference. Social workers should seek out knowledge about how different cultures perceive the importance of formal education. This may occur through informal conversations with students' families and/or community representatives. Social workers can help to create a culture that prevents racial inequality through shaping ideas and ideologies. An example of a cultural idea is that minority students are "at-risk". This idea perpetuates inequality in schools (O'Connor et al., 2009). Social workers should prevent placing students in categories based on race. They can also create a culture of addressing each student's academic progress individually. Social workers can advocate for using individualized, rather than categorized language. An example of a cultural ideology is the belief in the medical model, which focuses on individual diagnosis. Alternatively, social workers can promote the humanistic perspective, which posits that differences are contributions to the richness of educational settings (Mills, 2003). 


\section{Interpersonal}

As Collins (2009) elucidates, people are given the opportunity to accept or resist racial inequality in daily interactions. This is also true for social workers in their professional practice. Even though social workers are ethically responsible to advocate for social justice based on the Code of Ethics, they may not always conduct their work in ways that create social justice. To practice transformational resistance school social workers need to recognize how their daily action and interactions with others might reinforce the dominant culture. Collins (2009) explains that we need to ask ourselves how we individually foster racial domination or emancipation in our daily actions.

\section{IMPLICATIONS}

African American students have continued to be overrepresented in special education classrooms as strategies to eliminate the disproportionality have focused on teachers and schools as targets of intervention. It is critical to promote the inclusion of African American students with disabilities in classrooms with their typical peers, because the research has shown that students who are separated from regular education classrooms experience negative outcomes (Brown et al., 2003; Freeman \& Alkin, 2000; Hanushek et al., 2002; Harry \& Anderson, 1994). Although few scholars have discussed it, school social workers have a unique role in students' lives that empowers them to practice transformational resistance to the disproportionality of African American students in special education (Ebersole \& Kapp, 2007; Furr, 1993; Joseph et al., 2010; Mills, 2003). School social workers should participate in transformational resistance to eliminate disproportionality by creating change within and across the structural, disciplinary, cultural, and interpersonal power domains in the following methods: 1) attending IEP meetings and conducting home visits and biopsychosocial evaluations with students who are being assessed for special education services, 2) offering to evaluate and conduct home visits with students whom teachers deem to be "at-risk" to prevent inappropriate assessments for special education, 3) creating a school culture of acceptance of difference, and 4) asking themselves how they individually foster racial domination or emancipation in their daily actions.

This call for school social workers to change their practices also indicates that policy change is needed to empower social workers to eliminate disproportionality. Because the IDEA only mandates social workers to be members of child study teams and not IEP teams, school social workers may not be invited to IEP meetings or knowledgeable of when IEP meetings are being held. The IDEA and/or local educational agencies need to mandate school social workers to be members of IEP teams and to conduct home visits and biopsychosocial evaluations. As demonstrated with previous policy changes that were intended to impact African American students in education, mandates as well as funding are needed to create change. IDEA and local educational agency policy changes must also be matched with funding to hire the appropriate number of school social workers needed in each district to attend student IEP meetings. This would make it easier for school social workers to create change. In the meantime school social workers need to work collaboratively with teachers to change the structure of student assessments for special education. 
Though there are a few conceptual articles about social workers' role in the disproportionality of African American students in special education, this author found no empirical studies on social workers' participation in the diagnosis or classroom placement of African American students in special education. More research is needed to learn about school social workers' current role in special education diagnosis and placement and methods that social workers can improve their professional practices to eliminate the disproportionality. Collins (2009) provides a framework to understand how multiple domains of power impact racial inequalities. Structural, disciplinary, cultural, and interpersonal domains of power should be addressed in future research on how social workers can use transformational resistance to eliminate the disproportionality. This will help to illustrate how each domain is impacting the overrepresentation of African American students in special education and how social workers can support racial equality in education.

\section{References}

Artiles, A. J., Kozleski, E. B., Trent, S. C., Osher, D., \& Ortiz, A. (2010). Justifying and explaining disproportionality, 1968-2008: A critique of underlying views of culture. Exceptional Children, 76(3), 279-299.

Blanchett, W. J. (2006). Disproportionate representation of African American students in special education: Acknowledging the role of white privilege and racism. Educational Researcher, 35(6), 24-28.

Bronstein, L. R., Ball, A., Mellin, E. A., Wade-Mdivanian, R. \& Anderson-Butcher, D. (2011). Advancing collaboration between agency-employed school-based social workers: a mixed methods comparison of competencies and preparedness. Children \& Schools, 33(2), 83-95.

Brown, M. R., Higgins, K., Pierce, T., Hong, E., \& Thomas, C. (2003). Secondary students' perceptions of school life with regard to alienation: The effects of disability, gender and race. Learning Disability Quarterly, 26(4), 227-238.

Chemerinksy, E. (2002). The segregation and resegregation of American public education: The courts' role. North Carolina Law Review, 81, 1597-1622.

Collins, P. H. (2009). Another kind of public education. Boston, MA: Beacon Press.

Council on Social Work Education (CSWE). (2008). Educational policy and accreditation standards. Washington, DC: Author.

Ebersole, J. L., \& Kapp, S. A. (2007). Stemming the tide of overrepresentation: Ensuring accurate certification of African American students in programs for the mentally retarded. School Social Work Journal, 31(2), 1-16.

Freeman, S. F. N., \& Alkin, M. C. (2000). Academic and social attainments of children with mental retardation in general education and special education settings. US: Hammill Institute on Disabilities. doi:10.1177/074193250002100102 
Furr, L. A. (1993). Curriculum tracking: A new arena for school social work. Social Work in Education, 15(1), 35-44.

Hanushek, E. A., Kain, J. F., \& Rivkin, S. G. (2002). Inferring program effects for special populations: Does special education raise achievement for students with disabilities? The Review of Economics and Statistics, 84(4), 584.

Harry, B., \& Anderson, M. (1994). The disproportionate placement of African American males in special education programs: A critique of the process. The Journal of Negro Education, 63(4), 602-619.

Hopson, L., \& Lawson, H. (2011). Social workers' leadership for positive school climates via data-informed planning and decision making. Children \& Schools, 33(2), 106118.

Individuals with Disabilities Education Improvement Act, Pub. L 108-446, 20 U.S.C. 1400 et. seq.,118 Star. 2647 (2004).

Joseph, A. L., Jr., Slovak, K., \& Broussard, C. A. (2010). School social workers and a renewed call to advocacy. School Social Work Journal, 35(1), 1-20.

Kelly, M. S., Frey, A. J., \& Anderson-Butcher, D. (2010). School social work practice: directions based on present conditions. Children \& Schools, 32(4), 195-199.

Ladson-Billings, G. (2009). Just what is critical race theory and what's it doing in a nice field like education? In E. Taylor, D. Gillborn \& G. Ladson-Billings (Eds.), Foundations of critical race theory in education (pp. 17-36). New York, NY: Routledge.

Mills, C. (2003). Reducing overrepresentation of African American males in special education: The role of school social workers. Race, Gender \& Class, 10(2), 71-83.

National Association of Social Workers. (approved 1996, revised 1999). Code of ethics. Washington, DC: Author.

O’Connor, C., Hill, L. D., \& Robinson, S. R. (2009). Who's at risk in school and what's race got to do with it? Review of Research in Education, 33, 1-34. doi:10.3102/0091732X08327991

Skiba, R. J., Poloni-Staudinger, L., Gallini, S., Simmons, A. B., \& Feggins-Azziz, R. (2006). Disparate access: The disproportionality of African American students with disabilities across educational environments. Exceptional Children, 72(4), 411-424.

Skiba, R. J., Simmons, A. B., Ritter, S., Gibb, A. C., Rausch, M. K., Cuadrado, J., \& Chung, C. (2008). Achieving equity in special education: History, status, and current challenges. Exceptional Children, 74(3), 264-288.

Solorzano, D. G., \& Bernal, D. D. (2001). Examining transformational resistance through a critical race and LatCrit theory framework: Chicana and Chicano students in an urban context. Urban Education, 36, 308-342. doi:10.1177/0042085901363002 
U.S. Census Bureau. (2010). Current Population Survey, Annual Social and Economic Supplement. Retrieved from

http://www.census.gov/population/www/socdemo/race/ppl-ba10.html

\section{Author note:}

Address correspondence to: Kristen Faye Bean, M.A., MSW, Arizona State University School of Social Work, 411 N. Central Avenue, Suite 800, Phoenix, AZ 85004. Email: kfbean@asu.edu 